\title{
Some Paleopathological Cases from a Medieval Necropolis of Drustar (Silistra), Bulgaria (Investigation of the Postcranial Skeletons) \\ Diana Toneva
}

\author{
National Anthropological Museum with Research group, \\ Institute of Experimental Morphology, Pathology and Anthropology with Museum, \\ Bulgarian Academy of Sciences, Sofia, Bulgaria \\ E-mail: ditoneva@abv.bg \\ Silviya Nikolova \\ National Anthropological Museum with Research group, \\ Institute of Experimental Morphology, Pathology and Anthropology with Museum, \\ Bulgarian Academy of Sciences, Sofia, Bulgaria
}

\section{Doi:10.5901/mjss.2013.v4n11p603}

\section{Abstract}

Drustar was a medieval town in Northeastern Bulgaria. It was the most important fortress in the Lower Danube. The bone material was excavated from a necropolis situated near to the north wall of the fortress. The burials were dated in $9^{\text {th }}-15^{\text {th }}$ century $A D$. The study included postcranial skeletons of 147 individuals (42 children and 105 adults). There were observed traces of pathological changes in the different bones of the postcranial skeleton, such as fractures, osteoarthritis, spina bifida, etc. The degenerative disorders of the joints were most often occurred. The results obtained suggest that living conditions were not very favourable for the medieval population of Drustar.

\section{Introduction}

Paleopathology is the study of disease that affected living organisms in the past (Ortner, 2011). It is a discipline that aims to trace the origin, evolution and history of disease over long periods of time through pathological changes which represent diseases suffered in life and observed in human remains buried at archaeological sites (Roberts et al., 2012). Most studies in palaeopathology are focused on the skeletal remains, because these are the human remains that are most commonly preserved and excavated from archaeological sites. The paleopathological examination gives an idea of the frequency, dissemination and seriousness of the disease. Moreover, the data collected give additional information about the way of living of the studied population.

In our study we investigated bone material from Drustar, a medieval town in Northeastern Bulgaria. It was the most important fortress in the Lower Danube. For that reason the data about the occurrence of diseases in the population of medieval Drustar are very valuable.

\section{Material and Methods}

The bone material was excavated from a necropolis situated near to the north wall of the fortress. The burials were dated in $9^{\text {th }}-15^{\text {th }}$ century AD. The study included postcranial skeletons of 147 individuals -42 children and 105 adults (Table 1). The sex and age were determined previously by metrical and morphological features of the skull and postcranial bones. The identification of paleopaleopathological conditions was performed particularly by macroscopical observation. The material was not sufficient for statistical analysis, since the most skeletons were fragmentary or incomplete.

Table 1. Sex and age distribution of the buried individuals

\begin{tabular}{|c|c|c|c|c|}
\hline \multirow{2}{*}{ Age categories } & \multirow{2}{*}{ Children } & \multicolumn{4}{|c|}{ Sex } \\
\cline { 3 - 5 } & & Male & Female & Undetermined \\
\hline Infans I (0-7) & 28 & - & - & - \\
\hline
\end{tabular}




\begin{tabular}{|c|c|c|c|c|}
\hline Infans II (7-14) & 14 & - & - & - \\
\hline Juvenilis (14-20) & - & - & 2 & - \\
\hline Adultus (20-40) & - & 34 & 28 & 1 \\
\hline Maturus (40-60) & - & 26 & 11 & 1 \\
\hline Senilis (over 60) & - & 1 & 1 & - \\
\hline Total & 42 & 61 & 42 & 2 \\
\hline
\end{tabular}

\section{Results and discussion}

During the paleopathological study, a large range of pathological changes were discovered in the skeletons. According to our results, we classified the paleopathological findings into four categories: joint diseases, congenital anomalies, traumatic and infection conditions.

\subsection{Joint diseases}

Degenerative damages of the bones and joints were established in 27 adult individuals. The pathological processes affecting joints of the spine were predominantly found. We observed them more frequently in males than in females and majority of individuals were over the age of 35 years. According to Dieppe and Lim (1998), spinal osteoarthritis occurred in almost everyone over the age of 40. Aufderheide and Rodriguez-Martin (1998) noticed that the Caucasians were more often affected in comparison with the Black people.

In most cases osteoarthritis is slowly progressive and bone changes are preceded by alterations of the articular cartilage. Pathological features such as subchondral bone eburnation, sclerosis and development of osteophytes in archaeological skeletal remains reflect the later stages of osteoarthritis or its more severe manifestations (Ortner, 2003). Our observation showed that the vertebral bodies were the most often affected with wide range of alterations. In most cases vertebral bodies are strongly deformed by osteophytes with different size - from small bone spurs to big beak-like exostoses (Fig. 1). There were occurred osteophytic bone bridges between adjacent vertebral bodies as well.

Fig. 1. Osteophytosis (male, maturus)

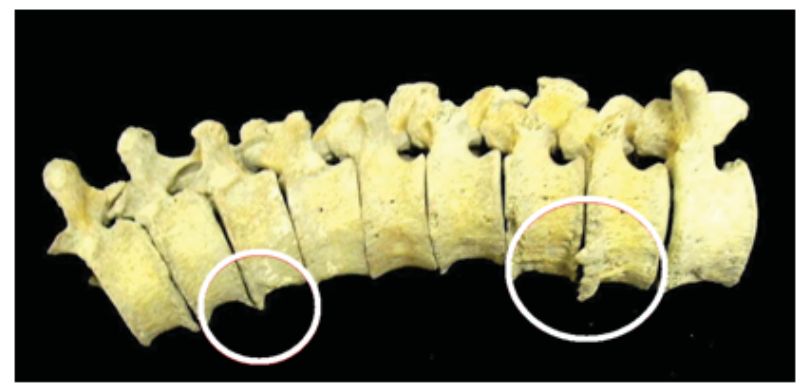

The degenerative changes in the investigated population were most often localized in thoracic and lumbar parts of the spine. After Duthie and Bentley (1987) the most commonly involved locations are lower cervical (C5-C6), lower thoracic (T8-T9) and lower lumbar (L4-L5). As far as the changes in the cervical vertebrae are concerned, our observation showed that C2-C3 were most often affected.

Besides spinal osteoarthritis in this population, degenerative changes in the joints of the extremities were found. Our results showed that the morphological changes such as thickening around the joint margins, formation of osteophytes and polishing of the exposed bony articular surfaces were localized mainly on knee and elbows. The polished areas are absolutely diagnostic of severe osteoarthritis and are more typical in joints with a hingelike action (Ortner, 2003). In one of our cases was observed severe form of the degenerative changes in the knee (Fig. 2), which was concomitant with spondylotic changes in the spine. Aufderheide and Rodriguez-Martin (1998) noticed that knee is the most commonly involved joint, especially in females. 
Fig. 2. Osteoarthritis in the knee of a mature individual

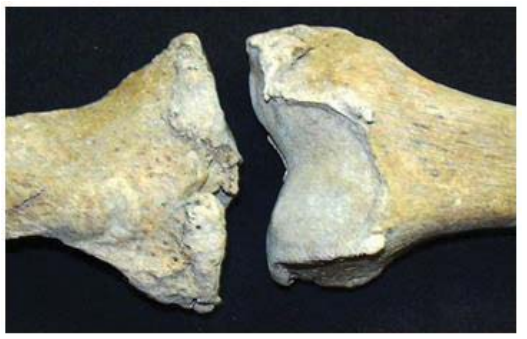

The results we obtained coincide with the data supplied for the spread and frequency of the degenerative processes during the Middle Ages in Bulgaria (Boev et al., 1980; Boev et al., 1981; Kondova et al., 1982, Goranov et al., 1983). Tcholakov (1993), who investigated the skeletal remains form the same place, but the necropolis was revealed beside the southern fortress wall and dated $12^{\text {th }}-14^{\text {th }}$ century $A D$, found similar pathological picture of degenerative joint diseases.

We observed a case of extensive hyperostosis in which the diagnosis of Difuse Idiopathic Skeletal Hyperostosis (DISH) was very likely. It was found in a male of 40-50 years (Fig. 3).

Fig. 3. Diffuse idiopathic skeletal hyperostosis (male, maturus)

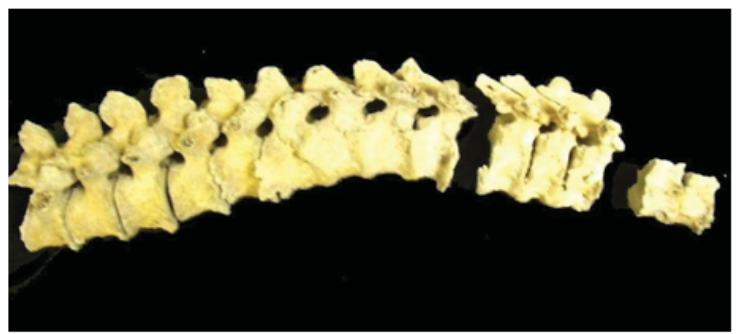

Aufderheide and Rodriguez-Martin (1998) noticed that DISH is rarely detected before age 40 years. As a matter of fact, DISH is a metabolic disorder. The main feature of DISH is a tendency to produce excessive amounts of bone at joint margins and the entheses. This is particularly apparent in the spine, but other locations in the skeleton may also be affected (Ortner, 2003). DISH is about twice as common in males as in females and the condition increases in prevalence with age (Smythe and Littlejohn, 1998). Additional considerations include the absence of disk disease and the presence of relatively normal diathrodial joints in the affected vertebrae (Ortner, 2003).

\subsection{Congenital anomalies}

Congenital anomalies are produced by pathological changes in the normal development during intrauterine life (Aufderheide and Rodriguez-Martin, 1998). The most common malformations in our sample occurred in the sacral region of the spine. Spina bifida occulta is a congenital malformation where the osseous median line is incompletely closed. Varying degrees of spina bifida are a commonly mentioned abnormality in reports of archaeological speciments (Ortner, 2003). It appears in the majority of the cases in the lumber-sacral region of the spine, especially at the level of the sacrum bone. In our sample, spina bifida was found in three males with the death age of 20-25 years (Fig. 4). The sacrum bones of these cases present total occult sacral dysraphism - S1-S5, forming a channel between the laminas. Spina bifida was also observed in one more individual (male, 20-25 years), but it was partial and the sacrum bone had dorsal inter-laminar dehiscence only at the level of segments S3-S5. Groza et al. (2012) reported that the occult spinal sacral dysraphism in case of the medieval population of laşi, Romania, appeared in 6 cases ( 5 men with ages between 18 and 60 and one woman with the age between $18-20$ years). 
Fig. 4. Spina bifida in two adult males

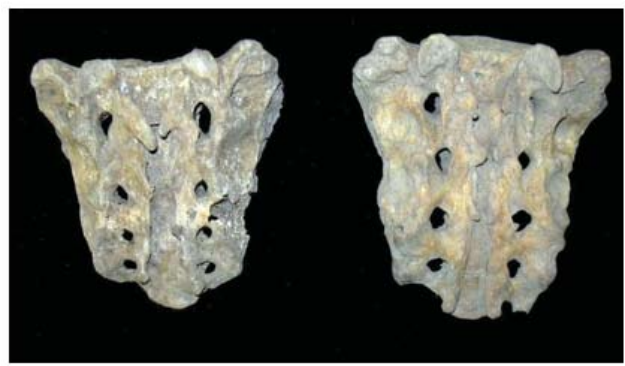

The sacralization of the $5^{\text {th }}$ lumbar vertebra is other congenital defect in the case of which this vertebra fusions with the sacrum bone so that the lumbar spinal column loses a segment. We observed it in three individuals. The morphologic aspect of the sacrum bone is normal but it presents a supplementary sacral foramen (Groza et al., 2012). It is asymptomatic in many cases, but occasionally may cause low back pain.

\subsection{Traumatic and infection conditions}

Traumas are another group of pathological findings, which is one of the most prevalent conditions encountered. The causes of trauma include accidental and intentional violence, cultural cosmetic or therapeutic practices, that affect bones, and pathological conditions that can increase the vulnerability of bone to biomechanical stress (Ortner, 2003). It is important to be noticed, that trauma occurring the time of death can easily be confused with postmortem taphonomic breaks in bone (Ortner, 2003).

Fractures are a type of traumas, which represent partial or complete discontinuity of a bone. All five fractures in our sample were well healed, indicating survival after the trauma. We found fractures of the ulna in three cases. Tcholakov (1993) also found that the most common were fractures of the forearm bones, especially the ulna. In one of these cases, observed in a male over the age of 50, the trauma was healed without displacement, but with a thorn-like ossified projection arising from the place of the fracture e.g. there was a presence of traumatic myositis ossificans (Fig. 5). Myositis ossificans traumatica is usually produced by avulsion of tendinous and/or muscle attachment to bone, generating a hematoma (Aufderheide and Rodriguez-Martin, 1998). The periosteum may participate in the organization of the hematoma including ossification. In another individual (male, 40-50 years) with a healed fracture of the right ulna was observed a healed skull fracture as well, which suggests that both fractures were very likely to have been occurred simultaneously, while the man had tried to guard himself with his arm against the attacker.

Fig. 5. Ulna fracture (male, maturus)

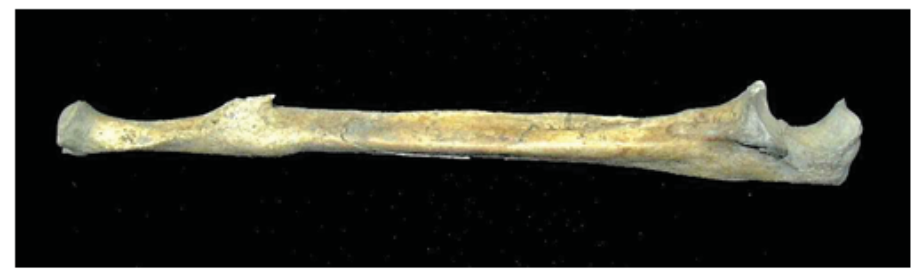

A fracture of the left femur was observed in an adult female (Fig. 6). This fracture was healed with angulation, which must have resulted in a shortened bone and provided at least limited use of the limb. There was callus formation around the place of the fracture and few cloacae at the site of the fracture on the posterior aspect of the shaft, indicating secondary infection by osteomyelitis. Posttraumatic osteomyelitis is most commonly observed in the cranium and long bones of archaeological skeletons (Lovell, 1997). 
Fig. 6. Femur fracture (female, adultus)

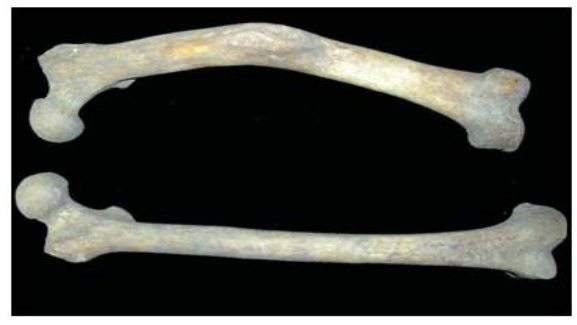

Sometimes breaks occurred in more than one bone; as it is seen in the case of an individual where a combined tibia/fibula fracture of the right leg was observed (Fig. 7). Both bones were knitted together with displacement of the fragments and the entire lower leg must have been shortened. This fracture was concomitant with damages of the overlying muscles and subsequently developed myositis ossificans traumatica.

Fig. 7. Combined tibia/fibula fracture (male, maturus)

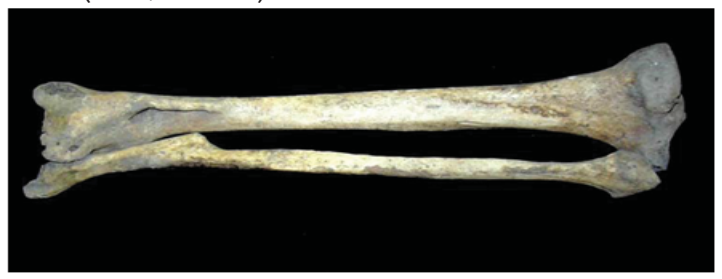

However, myositis ossificans traumatica may occur without obvious skeletal injury and after trivial muscle trauma (Apley, 1981; Aufderheide and Rodriguez-Martin, 1998). An irregular calcified mass was observed on the posterior surface of tibia in a male at age of death in his 40 s (Fig. 8). It probably represents calcified crushed muscle.

Fig. 8. Myositis ossificans traumatica (male, maturus)

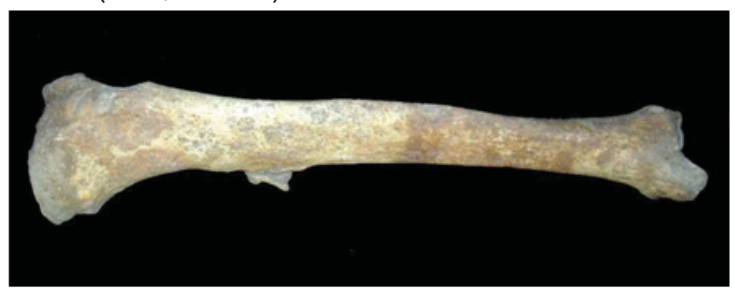

On the long bones of the right leg of an adult female was found new bone formation indicating active infection (periostitis) at the time of death (Fig. 9).

Fig. 9. Periostitis of long bones (female, adultus)

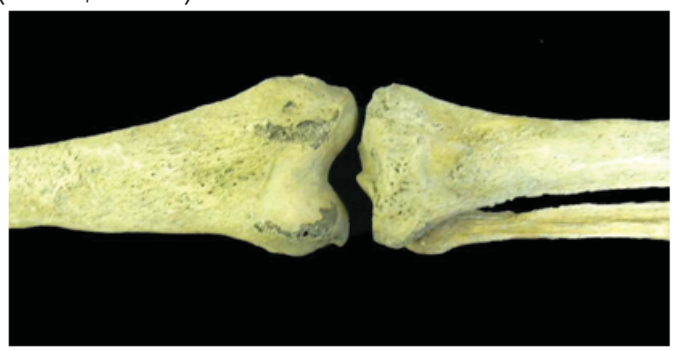


Periostitis is usually non-specific, and occurs in many diseases. It may be due to infection, as in the case of osteomyelitis, or result from trauma or even in the recovery phase of deficiency syndromes (e.g. vitamin C deficiency). In the case of syphilis the lesions are commonly found on bone surfaces close to the skin, e.g. anterior surface of the tibia (Steyn and Işcan, 2000). It is also considered, that bones are impacted when the person's resistance is low due to poor nutrition and stress.

\section{Conclusion}

The paleopathological investigation of the medieval population of Drustar showed that different pathological conditions were observed in more than one third of the adult individuals. The degenerative diseases of the spine were most often occurred. The data obtained suggest that living conditions were not very favourable for this population, confirming the results of Tcholakov (1993).

\section{Acknowledgments}

This work was supported by the European Social Fund and Republic of Bulgaria, Operational Programme "Human Resources Development" 2007-2013 framework, Grant № BG051P0001-3.3.06-0048 from 04.10.2012.

\section{References}

Apley, A. G. (1981). Ortopedia y Tratamiento de Fracturas. Barcelona: Salvat.

Aufderheide, A.C. \& Rodriguez-Martin, C. (1998). The Cambridge Encyclopedia of Human Paleopathology. Cambridge: Cambridge University Press.

Boev, P., Kondova, N. \& Cholakov, SI. (1981). Zabolyavaniya i travmi v srednovekovna Bulgaria. Dokladi, I Natsionalen kongres po istoriya na medicinata, Shumen, 38-48. lin Bulgarian/

Boev, P., Stefanov, V., Kondova, N. \& Cholakov, SI. (1980). Paleopatologichno prouchvane na srednovekovni populatcii ot Bulgaria. Higiena i zdraveopazvane, 6, 583-589. lin Bulgarian/

Dieppe, P. \& Lim, K. (1998). Clinical features and diagnostic problems. In J. Klippep and P. Dieppe (ad.), Rheumatology (2nd ed.). London: Mosby.

Duthie, R.B., Bentley, G. (1987). Cirugía Ortopédica de Mercer. Barcelona: Medici.

Goranov, I., Boev, P., Kondova, N., Cholakov, S., 1983. Paleopathological data for the spinal column diseases. Acta Morphologica, 4, 57-63.

Groza, V., Simalcsik, A. \& Bejenaru, L. (2012). Frequency of spina bifida occulta and other occultspinal dysraphisms in the medieval population of laşi city: skeleton paleopathology in the necropolis discovered in the eastern part of the Princely Court ("Curtea Domneasă"), 17th century. Biologie animală, LVIII, 195-204.

Kondova, N., Boev, P. \& Tcholakov, Sl. (1982). Paleopathology of the medieval Bulgarian population. Man and his origins, Anthropos /Brno/, 21, 379-382.

Lovell, N.C. (1997). Trauma Analysis in Paleopathology. Yearbook of Physical Anthropology, 40, 139-170.

Ortner, D. (2003). Identification of pathological conditions in human skeletal remains. San Diego: Academic Press.

Ortner, D. (2011). What skeletons tell us. The story of human paleopathology. Virchows Archiv, 459(3), 247-254. doi:10.1007/s00428011-1122-x

Roberts, C.A., Alves Cardoso, F., Bernofsky, K., Henderson, C., Jakob, T., Plomp, K., ... Spencer, R. (2012). Palaeopathology: studying the origin, evolution and frequency of disease in human remains from archaeological sites. UNESCO EOLSS.

Smythe, H., Littlejohn, G. (1998). Diffuse idiopathic skeletal hyperostosis. In Klippel, J.H. \& Dieppe, P.A. (Eds.), Rheumatology (2nd ed., pp 10.1 - 10.6). London: Mosby.

Steyn, M. \& Işcan, M. (2000). Bone pathology and antemortem trauma in forensic cases. In Siegel, J.A., Saukko, P.J. \& Knufer, G.C. (Eds.), Encyclopedia of Forensic Sciences Academic (pp. 217-227), London: Academic Press. doi:10.1006/rwfs.2000.0759.

Tcholakov, Sl. (1993). An anthropological study of a medieval cemetery at the city of Drustur. Annuaire de l'universite de Sofia "St. Kliment Ohridski", Faculte D' Histoire, 86, 105-133. 